\title{
Carcinoma of the ampulla of Vater: prognostic factors after curative surgery: a series of 45 cases
}

\author{
A Dorandeu, J-L Raoul, F Siriser, N Leclercq-Rioux, M Gosselin, E D Martin, M-P \\ Ramée, B Launois
}

Services d'Anatomie Pathologique A Dorandeu N Leclercq-Rioux M-P Ramée

\section{Service de} Gastroentérologie

J-L Raoul

M Gosselin

Service de Chirurgie Digestive, Centre Régional Hospitalier Universitaire de

Rennes

F Siriser

B Launois

Centre Régional de Lutte contre le Cancer, Eugène Marquis, Rennes

J-L Raoul

Service d'Anatomie Pathologique, Centre Régional Hospitalier Universitaire de Kremlin-Bicètre E D Martin

Correspondence to: Dr Jean-Luc Raoul, Centre Régional de Lutte contre le Cancer, Eugène Marquis, rue de la bataille Flandres-Dunkerque, Flandres-Dunkerque, Cédex, France.

Accepted for publication 28 November 1996

\begin{abstract}
Background-Some adjuvant or neoadjuvant therapy could be important for patients operated on for tumours of the ampulla of Vater, especially for those having a higher risk of recurrence.

Aim-To evaluate prognostic factors after curative surgery based on a series of 45 cases of malignant tumours of the Oddi sphincter.

Patients-From 1970 to 1992, a curative resection was performed in 45 patients (age 62.8 (SD 10.1) years) with adenocarcinoma of the ampulla. Surgical procedures included pancreatoduodenectomy $(n=42)$ and resection of the ampulla $(n=3)$. Actuarial survival was 44 (SD 9) $\%$ at five years.
\end{abstract}

Methods-Various prognostic variables were studied: clinical manifestations, macroscopic aspect, differentiation, noninvasive adenomatous component, mucin histochemistry, immunohistochemistry (CEA, CA19.9, p53, Ki67), and accepted classifications (Blumgart and Kennedy, Martin, Yamaguchi and Enjoji, Talbot et al, pTNM).

Results-Variables with prognostic power, in order of importance were: Classification of Talbot et al; CA19.9; pTNM; sialomucins; classification of Yamaguchi and Ejoji; Martin classification; sulphomucins; non-invasive adenomatous component (positive>negative); jaundice; tumour localisation.

Conclusions-This series confirmed the prognostic power of former classifications and showed the prognostic power of other variables (mucin, non-invasive adenomatous component, CA19.9).

(Gut 1997; 40: 350-355)

Keywords: ampulla of Vater, carcinoma, surgery, immunohistochemistry, p53.

Primary malignant tumours rarely occur in the ampulla of Vater. Pancreatoduodenectomy with or without resection of the pylorus is the procedure of choice. Prognosis is radically different from tumours of the head of the pancreas as five year survival after complete surgical resection is $30 \%$ to $60 \%$. Several adjuvant postoperative treatments have been proposed in an attempt to improve survival rates. Splinter $e t a l^{1}$ did not find any improvement in three year survival after chemotherapy. Willet et $a l^{23}$ proposed postoperative ir- radiation with or without 5 -fluorouracil for their patients and noted a reduction in the rate of local recurrence but no beneficial effect on survival. A recent randomised controlled study in Scandinavia ${ }^{4}$ showed a significant improvement in mean overall survival and in two year survival after postoperative chemotherapy in patients undergoing curative surgery for cancer of the head of the pancreas or the papilla (14/61 cases). The implications of these results are, however, subject to discussion as the series were either non-randomised, or included only a few patients, or reported cancer of the pancreas and the papilla together. In addition, as for adenocarcinoma of the colon, the rationale for treating all patients undergoing what is considered to be a curative surgical procedure is not always clear. A more appropriate approach would be to reserve adjuvan therapy for patients at higher risk of recurrence. There are indeed several classifications aimed at predicting prognosis. More recently, certain criteria based on histochemistry (mucin typing) or immunohistochemistry (CEA, C19.9, Ki67, or p53) have been useful for other types of tumours. In this retrospective study we evaluated clinical, histological, histochemical, and immunohistochemical criteria of prognosis with specia focus on recent histochemical or immunological labelling, in patients who underwent curative surgery for tumours of the ampulla of Vater.

\section{Methods}

Between 1 January 1970 and 31 December 1992 curative surgery was performed on 45 patients for primary malignant tumours of the ampulla of Vater and histologically demonstrated invasion of the basal membrane. Patients who were treated with a palliative procedure (as defined operatively) or had invaded margins (in the pathology report) and those who had an in situ lesion or dysplasia were excluded from the study.

Age, sex, signs leading to diagnosis (jaundice, pain, anaemia, bleeding), and preoperative endoscopical findings were obtained from the hospital records of the 45 patients. After surgery, the macroscopic aspect of the tumour (vegetating, nodular, ulceration), the largest diameter, and initial localisation (true tumour of the ampulla, or tumour arising from periampullary duodenal surface mucosa, from the common bile duct, or pancreatic duct) were recorded. All pathology slides were then reviewed prospectively focusing on infiltration of the tumour, 
degree of malignancy, and differentiation according to the criteria of Von Dinges.

These data were used to assign patients in the following classifications: (1) initial and modified Blumgart and Kennedy classifications $^{5}$; (2) four stages in the classification of Martin: ${ }^{6}$ stage $I=$ vegetating tumour limited to the epithelium with no involvement of the Oddi sphincter, stage II=tumour localised in the duodenal submucosa without involvement of the duodenal muscularis propria but possible involvement of the Oddi sphincter, stage III=tumour of the duodenal muscularis propria, stage IV=tumour of the periduodenal area or the pancreas with proximal or distal lymph node involvement; (3) Classification of Yamaguchi and Enjoji, ${ }^{7}$ very similar to the Martin classification; ${ }^{6}$ (4) Classification of Talbot $e t a l^{8}$ associating an infiltration score (from 1 to 4 according to increasing degrees of infiltration) and a tumour differentiation score (from 1 to 3 for well, medium, and poorly differentiated tumours) giving a sum which separates the patients into group 1 with a sum from 2 to 4 and group 2 with a sum from 5 to 7; and (5) the pTNM classification, in which stages are defined as: $\mathrm{T} 1=$ lesion limited to the ampulla, T2=invasion of the duodenal wall, $\mathrm{T} 3=$ invasion of the pancreas extending less than $2 \mathrm{~cm}$, and $\mathrm{T} 4=$ invasion of the pancreas extending further than $2 \mathrm{~cm}$, each patient is then assigned to stage $\mathrm{I}=\mathrm{T} 1 \mathrm{~N} 0$, stage $\mathrm{II}=\mathrm{T} 2-$ $3 \mathrm{~N} 0$, stage III $=\mathrm{T} 1-3 \mathrm{~N} 1$, or stage $\mathrm{IV}=\mathrm{T} 4$ anyN .

Finally the presence or absence of an adenomatous component was identified according to the recent description by Yamauchi et $a l^{9}$ who determined that there is an adenomatous component if the glandular structures forming the adenomas lying near the carcinomas cover at least $20 \%$ of the total surface area of the tumour.

Evidence of mucin secretion and the type of mucin secreted was then prospectively obtained with PAS and Alcian blue staining at $\mathrm{pH}$ 2.5 to separate neutral and acid mucins. Acid mucins were then divided into sulphomucins and sialomucins with a combined high iron diamine and Alcian blue staining at $\mathrm{pH} 2 \cdot 5$. Results were expressed semiquantitatively as: no secretion $=0$, secretion by less than $50 \%$ of the tumour cells $=+$, and secretion by more than $50 \%$ of the tumour cells $=++$. Tumours with or without neutral mucin secretion and tumours with or without predominant secretion or sulphomucin and sialomucin (including cases with exclusive secretion of these types of mucins and cases with mixed and predominant secretion) were also identified for the prognostic study.

Four antibodies were used for the immunohistochemistry study: CEA, CA19.9, p53, and Ki67. Anti-CEA II7 monoclonal antibodies (Dako laboratories) specific for the Gold 1 epitope were used to detect CEA. Monoclonal TM clone (CisBiointernational, Saclay, France) was used to detect C19.9. Monoclonal DO7 (Dako laboratories) was used to detect p53 protein. Finally, an anti-Ki67 MiB1 clone (Immunotech laboratories) was used for Ki67. Streptavidin-biotin coupled with peroxidase was used to label these four antibodies. Final detection was based on antigen-antibody reactions with colorimetric detecting using $\mathrm{H}_{2} \mathrm{O}_{2}$ and chromogenic 3,3 diaminobenzidine tetrahydrochloride (DAB). Anti-CEA and anti-CA19.9 immunolabelling were expressed semiquantitatively as: no labelling $=0$, labelling on at least one third of the tumour surface area $=+$, labelling of at least two thirds of the tumour surface area $=++$, and labelling of the entire tumour surface area $=+++$. Labelling distribution was also noted as apical or diffuse. Results for anti-p53 and anti-Ki67 were determined as the mean of 10 fields with a $X$ 400 magnification. Results were expressed as percentage of labelled cells.

\section{Statistical analysis}

Mean (SD) was used to analyse quantitative variables. Kaplan-Meier curves were drawn to evaluate specific survivals and were compared using the log rank test or the generalised Wilcoxon test. For the two continuous variables, anti-p53 and anti-Ki67 labelling, the cut off point was set at $5 \%$ for $\mathrm{p} 53$ and at $15 \%$ for Ki67. The $\chi^{2}$ test and the exact Fisher test were used to analyse the association of several variables for prognostic value. Significance was set at $5 \%$.

\section{Results}

\section{Descriptive analysis}

There were 45 patients -25 men and 20 women, mean age 62.8 (SD 10.1) (range 13-80) years. The youngest patient was a women with familial adenomatous polyposis (the only patient with a similar clinical situation in this study). The most frequent clinical signs were jaundice $(n=32,71 \%)$, abdominal pain $(n=26,58 \%)$, anaemia $(n=9$, $20 \%)$, and haemorrhage $(n=5,11 \%)$. The delay between onset of symptoms and diagnosis was short (3 (SD 2.8) months). Weight loss was noted in $51 \%$ of the cases. Preoperative endoscopical biopsies were obtained for 29 patients and were positive in $23(80 \%)$. Pancreatoduodenectomy was performed in 37 cases $(82 \%)$, pancreatoduodenectomy with resection of the entire pancreas in five cases $(11 \%)$, and ampullectomy alone in three cases $(7 \%)$. Three patients $(6 \cdot 7 \%)$ died during the immediate postoperative period and overall postoperative morbidity was $22 \%$ (three haemorrhages, three major infections, two abscesses, and one case each of respiratory complications and ulceration of the anastomosis).

Macroscopically the tumours measured $2 \cdot 5$ (SD 1.9) $\mathrm{cm}$ in diameter. There were 21 vegetating tumours $(47 \%), 14$ nodular tumours $(31 \%)$, and 10 ulcerated tumours $(22 \%)$. Strictly ampullary localisation was seen in 28 cases $(62 \%)$. Other localisations were: lower end (within the Oddi sphincter and ampulla) of the common bile duct $(n=5,11 \%)$; end (within the Oddi sphincter and ampulla) of the pancreatic duct alone $(n=1)$; periampullary 


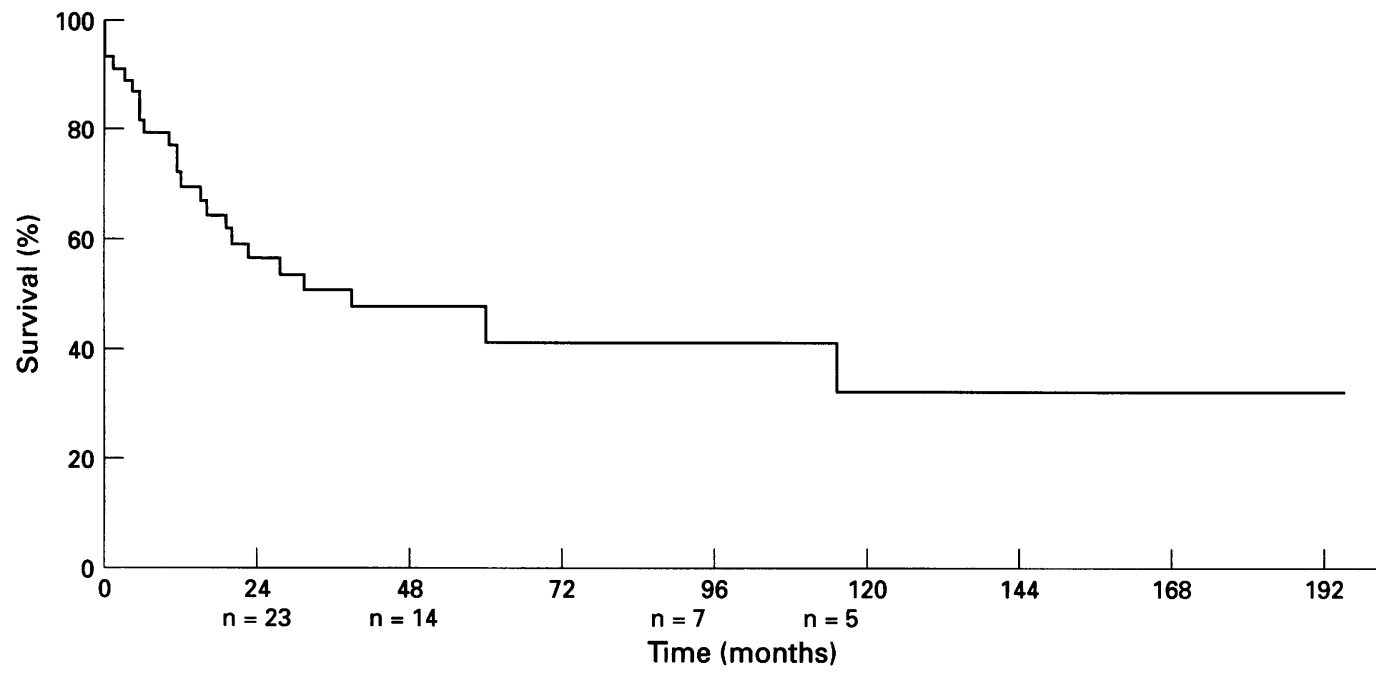

Actuarial survival of patients with carcinoma of the ampulla of Vater after curative resection.

duodenal surface mucosa ( $n=11,25 \%)$. Microscopically a non-invasive adenomatous component was seen in 16 cases $(35.6 \%)$.

Histochemistry disclosed secretion of neutral mucins in 25 cases (56\%), sialomucins in $22(49 \%)$, and sulphomucins in $34(76 \%)$. Sialomucin secretion predominated in 10 cases $(22 \%)$ and sulphomucin secretion in 31 $(67 \%)$.

Immunolabelling for CEA was negative or weak in 22 tumours (49\%) and very positive in $23(51 \%)$. Apical localisation was found in 14 and cytoplasmic labelling in 25. Labelling for CA19.9 was negative or weak in 13 cases and strongly positive in 32 with an apical distribution in nine and cytoplasmic labelling in 34 . Immunolabelling for p53 was detected in 22 cases (49\%) and for Ki67 in $23(51 \%)$.

Table I shows the results of the different classifications of patients. The probability of survival at two years was 60 (SD 7)\%, at five years it was $44(9) \%$, and at 10 years 38 (SD

TABLE I Results of six classifications of 45 patients who underwent curative surgery of cancer of the ampulla of Vater

\begin{tabular}{|c|c|}
\hline Classification & $\begin{array}{l}\text { Patients } \\
n(\%)\end{array}$ \\
\hline \multicolumn{2}{|c|}{ Blumgart and Kennedy5: } \\
\hline I & $13(29)$ \\
\hline IIa & $8(18)$ \\
\hline IIb & $8(18)$ \\
\hline IIc & $4(9)$ \\
\hline III & $12(27)$ \\
\hline \multicolumn{2}{|c|}{ Blumgart and Kennedy (modified): } \\
\hline I & $7(16)$ \\
\hline II & $19(42)$ \\
\hline III & $19(42)$ \\
\hline \multicolumn{2}{|l|}{ Talbot $e t a l^{8}$ : } \\
\hline I & $33(73)$ \\
\hline II & $12(27)$ \\
\hline \multicolumn{2}{|l|}{ Martin ${ }^{6}$ : } \\
\hline I & $4(9)$ \\
\hline II & $2(4)$ \\
\hline III & $23(51)$ \\
\hline $\mathrm{IV}$ & $16(35)$ \\
\hline \multicolumn{2}{|c|}{ Yamaguchi and Enjoji ${ }^{7}$ : } \\
\hline I & $4(9)$ \\
\hline II & $2(4)$ \\
\hline III & $25(56)$ \\
\hline IV & $14(31)$ \\
\hline \multicolumn{2}{|l|}{ pTNM: } \\
\hline I & $7(16)$ \\
\hline II & $29(64)$ \\
\hline III & $3(7)$ \\
\hline $\mathbf{I V}$ & $6(14)$ \\
\hline
\end{tabular}

12)\% (five patients at risk) (Figure). In all, 25 of the patients have died including the early postoperative deaths. The causes of death were: early postoperative death in three cases; in two cases death occurred early, less than one year after surgery, of unknown causes; one $\supset$ patient died after a myocardial infarction and $\vec{\varphi}$ in the others deaths were related to extension of the ampullary carcinoma.

\section{Prognostic factors}

Among the 22 factors studied, 11 were $\stackrel{\odot}{\perp}$ identified as having prognostic value. Table II $\overrightarrow{\vec{D}}$ gives their degree of significance and the five year survival rate in each sub-group. A positive correlation between prognostic factors was found in five of the possible combinations:

TABLE II Univariate analysis of prognostic variables in a series of 45 patients who underwent curative surgery for cancer of the ampulla of Vater

\begin{tabular}{|c|c|c|c|}
\hline Variable value & $\begin{array}{l}\text { Patients } \\
\text { (n) }\end{array}$ & $\begin{array}{l}\text { Survival } \\
\text { rate (\%) } \\
\text { at } 5 y\end{array}$ & p Value \\
\hline \multicolumn{4}{|c|}{ Position of tumour: } \\
\hline Ampulla & 28 & 54 & \multirow[t]{2}{*}{0.05} \\
\hline \multicolumn{3}{|c|}{ Site of CA19.9 labelling: } & \\
\hline Apical & 9 & 88 & \multirow[t]{2}{*}{$0 \cdot 04$} \\
\hline Cytoplasmic & 34 & 30 & \\
\hline \multicolumn{4}{|l|}{ Jaundice: } \\
\hline No & 13 & 75 & \multirow[t]{2}{*}{$0 \cdot 04$} \\
\hline Yes & 32 & 30 & \\
\hline \multicolumn{4}{|c|}{ Non-invasive adenomatous component: } \\
\hline $\begin{array}{l}\text { Yes } \\
\text { No }\end{array}$ & $\begin{array}{l}16 \\
29\end{array}$ & $\begin{array}{l}68 \\
27\end{array}$ & 0.03 \\
\hline \multicolumn{4}{|c|}{ Sulphomucin secretion: } \\
\hline No & 34 & 58 & \multirow[t]{2}{*}{0.02} \\
\hline $\begin{array}{l}\text { Yes } \\
\text { Martin classific }\end{array}$ & 11 & 32 & \\
\hline \multicolumn{4}{|c|}{ Martin classification: } \\
\hline $\begin{array}{l}\text { I + II } \\
\text { III + IV }\end{array}$ & 6 & $\begin{array}{r}100 \\
35\end{array}$ & 0.02 \\
\hline \multicolumn{4}{|c|}{ Yamaguchi and Enjoji classification: } \\
\hline $1+2$ & 6 & 100 & \multirow[t]{2}{*}{0.02} \\
\hline $3+4$ & 39 & 35 & \\
\hline \multicolumn{4}{|c|}{ Sialomucin secretion: } \\
\hline $\begin{array}{l}\text { Yes } \\
\text { No }\end{array}$ & 23 & 100 & \multirow[t]{2}{*}{$0 \cdot 007$} \\
\hline \multicolumn{3}{|l|}{ pTNM: } & \\
\hline I + II & 36 & 55 & \multirow[t]{2}{*}{0.003} \\
\hline $\begin{array}{c}\text { III + IV } \\
\text { CA19.9 intensi }\end{array}$ & 9 & 13 & \\
\hline $0,+$ & 13 & 92 & \multirow[t]{3}{*}{$0 \cdot 002$} \\
\hline,+++++ & 32 & 24 & \\
\hline \multicolumn{3}{|c|}{ Talbot et al classification: } & \\
\hline I & 33 & $\begin{array}{l}57 \\
10\end{array}$ & $0 \cdot 001$ \\
\hline
\end{tabular}


intensity and localisation of CA19.9 immunolabelling, non-invasive adenomatous component and the classification of Talbot $e t a l,{ }^{8}$ sialomucin secretion and Martin classification, classifications of Martin ${ }^{6}$ and Yamaguchi and Enjoji, ${ }^{7}$ and jaundice and the Martin classification. Eleven factors had no prognostic value: age ( $\leq$ or $>60$ years), sex, macroscopic aspect (vegetative, nodular, ulceration), tumour size, initial and modified Blumgart and Kennedy classifications, neutral mucin secretion (presence or absence), intensity and localisation of CEA labelling (apical, cytoplasmic), p53 labelling (positive, negative), and Ki67 labelling (positive, negative).

\section{Discussion}

This retrospective study of primary carcinomas of the ampulla of Vater showed that several factors have prognostic value. Some are well known, others are formerly unreported factors (CEA immunolabelling, mucin histochemistry, non-invasive adenomatous component).

This series confirms the exceptional nature of malignant tumour of the Vater ampulla as curative surgery was performed in only 45 cases over a 22 year period. During this same period, 22 other patients were also operated on for ampullary tumours: 14 underwent palliative surgery and eight were cured of dysplasia or in situ carcinoma of the ampulla of Vater. The rationale for not including patients who had undergone palliative surgery in this analysis of invasive malignant tumours was that the aim was to determine whether adjuvant or neoadjuvant treatments could be usefully proposed for patients with resectable tumours. The exclusion of non-invasive in situ tumours and dysplasias was motivated by the fact that such histological forms would not lead to the prescription of a complementary medical treatment.

The descriptive data obtained in this series are similar to those reported in the medical literature ${ }^{10-15}$ : mean age slightly over 60 years, slight male predominance, and frequent jaundice, pain, and haemorrhage. Survival at five years in our patients was 44 (SD 7)\%, which is high compared with that reported in the literature despite the exclusion of in situ tumours from the analysis. Preoperative endoscopical exploration, performed in 29 of our patients, gave the diagnosis of malignancy in $80 \%$. This is close to the diagnostic yield of endoscopical biopsies reported in one Japanese series, ${ }^{16}$ in which positive pathology results were obtained in $70 \%$. To improve endoscopical diagnosis, other endoscopical techniques, including biopsy after endoscopic sphincterotomy or snare biopsies, ${ }^{17}$ may be indicated.

Pancreatoduodenectomy is the treatment of choice for tumours of the ampulla of Vater. Local procedures such as simple ampullectomy have been proposed to reduce operative mortality. In a recent review, Allema et al ${ }^{12}$ reported lower mortality $(6 \%)$ and a better five year survival rate $(47 \%)$ for ampullectomy than for pancreatoduodenectomy $(12 \%-35 \%)$.
Early in our series we performed local resection in three cases. One patient had to be reoperated on for haemorrhage and the tumour recurred in all three patients. Pancreatoduodenectomy is well tolerated as confirmed by the outcome in this series (mortality $=6.7 \%$, morbidity $=22 \%$ ).

Multivariate analysis could not be performed due to the few patients and deaths $(n=24)$ in this series. However, data for 22 variables were analysed and 11 were found to have prognostic value. Among these there were five combinations showing correlations between two variables (exact Fisher test or $\chi^{2}$ test).

Neither age of the patients ( $>$ or $\leq 60$ years) nor sex had an effect on prognosis. However, all of the early deaths (immediate postoperative period or within six months of surgery) occurred in patients over 60 . The only clinical variable tested, jaundice, was found to have an unfavourable effect on prognosis. This finding, also reported by several other authors, ${ }^{1518}$ is related to the fact that jaundice is an expression of spread of disease ${ }^{14}$ just as is the association we found between the presence of jaundice and a more severe stage in the Martin classification.

Among the other macroscopic variables studied, neither tumour size nor the macroscopic aspect (vegetative, nodular, or ulceration) had prognostic value. Previous reports are contradictory. ${ }^{12}$ 15 19-22 The macroscopic histological classifications initially described by Blumgart and Kennedy ${ }^{5}$ and then modified by Martin, ${ }^{6}$ did not isolate any differences in prognosis. This may be related to the rather subjective nature of these classifications. The other macroscopic criterion examined, tumour localisation, was found to affect prognosis as tumours strictly limited to the ampulla had a better prognosis. This has previously been reported. ${ }^{1123}$ Tumours which originate at the sphincteral end of the pancreatic duct seem to have poor prognosis. ${ }^{11}$ It may, however, be difficult to distinguish the point of origin of extended tumours, and an analysis of mucin secretion can provide interesting results ${ }^{11}$ because different sets of tissues secrete different mucins. Neoplasia is, however, usually associated with a modification in mucin secretion which in itself may have prognostic power.

Most of the variables which had prognostic value were those distinguished by histology or histochemical or immunohistochemical methods. In this series, a non-invasive adenomatous component was associated with better prognosis. Adenomatous residues are often found within tumours of the ampulla ${ }^{24} 25$ confirming the fact that adenomas of the papilla are precancerous lesions, a finding which would be colloborated by the demonstration of increasing immunoreactivity to CEA and CA19.9 with increasing degrees of dysplasia. ${ }^{14}$ Adopting the criteria of Yamauchi et al to define the presence of adenomatous residues may be too restrictive, but the use of a cut off value $(20 \%)$ permits the differentiation of cases in which residues are important from those in which the area involved is minor 
or absent. There are two possible explanations as to why some cancers of the ampulla have no detectable adenomatous component. Either tumoural extension has already destroyed the adenomatous tissue or certain cancers develop without going through an adenoma stage. Such adenomatous residues are described in about one third of the cases of cancer of the colon ${ }^{26}$ and have a frequency inversely proportional to tumour size. Such an association has been suggested for tumours of the papilla ${ }^{25}$ but in two recently reported series, ${ }^{9}{ }^{27}$ as in ours, the authors were unable to show any relation. In addition, we found, as did Yamauchi et al in two series of 26 and 23 cases, ${ }^{9}{ }^{28}$ that there was a considerable difference in prognosis for tumours with a non-invasive adenomatous component. Such tumours showed a better prognosis (five year survival 78 and $75 \% v 22$ and $11 \%$ in the series of Yamaguchi et al and $68 \% v 27 \%$ in our series). It could thus be hypothesised that tumours without a noninvasive adenomatous component correspond to aggressive tumours with a rapid progression destroying the adenomatous tissue or to new tumours of the ampulla which have not gone through an adenoma stage; both cases would have a particularly severe prognosis. We also showed an association between the presence of a non-invasive adenomatous component and the Talbot classification, which takes into consideration both tumour infiltration and differentiation. This suggests that these tumours would also be less well differentiated. The four histology classifications examined here (Martin, ${ }^{6}$ Yamaguchi and Enjoji, ${ }^{7}$ pTNM, and Talbot et $a l^{8}$ ) all had prognostic power but because of the few patients, several stages had to be grouped together to show significance. These expected conclusions validate the quality of the other results. The classifications of Martin ${ }^{6}$ and Yamaguchi and Enjoji ${ }^{7}$ are similar and, as for the pTNM classification, are essentially based on tumour infiltration. Most studies have found that tumour infiltration has prognostic power, especially in patients with pancreatic ${ }^{2} 32122$ and lymph node involvement. ${ }^{2} 311152122$ The classification of Talbot et $a l^{8}$ based on parietal, pancreatic, and nodal infiltration and on the degree of tumour differentiation would seem to provide promising information. In our series, it produced the most discriminating classification. For most of the authors, 811152229 tumour differentiation affects prognosis and as the classification of Talbot et $a l^{8}$ uses both criteria for tumour infiltration and more cytological criteria (differentiation of cell architecture, cell differentiation, number of mitoses) it gives a better expression of the tumour cell status. Recent progress in genetics has shown that such cellular criteria sometimes have more prognostic power than clinical or histological criteria.

Histologically, the tissues in and around the Oddi sphincter are highly complex. There are four types of mucosa, each with a different pattern of secretion of mucus. In addition, it has been shown that neoplasic development in the gut is often associated with a modification in mucin production. ${ }^{30}$ Such modifications have also been suggested for cancers of the papilla. $^{31}$ The effect of tumorous mucin secretion on prognosis has only recently been approached. ${ }^{23}$ In a complete histochemical study, Dawson et $a l^{23}$ were able to divide acid mucins into sulphomucins and sialomucins and show that prognosis of intra-ampullar $\Omega$ tumours varies with the type of mucin secreted. Tumours secreting sialomucins would have a better prognosis. Our findings would favouro this hypothesis as the better prognosis waso found in tumours with predominant sialo- $\frac{\bar{m}}{\bar{D}}$ mucin secretion and in tumours without pre- $\mathbb{\Phi}$ dominant sulphomucin secretion.

We also analysed CEA, CA19.9, Ki67, and p53 expression using immunohistochemistry. The only effect on prognosis found was for $\vec{\omega}$ CA19.9, which seemed to have an unfavourable influence both for labelling intensity and localisation, which were associated. For ${ }_{0}$ certain authors, apical labelling is not an entity in itself, but rather corresponds to weaker w labelling than diffuse cytoplasmic labelling. ${ }^{22}$ The poor prognosis of CA19.9 positive cancers of the ampulla of Vater has been noted previously. ${ }^{142122}$ Whether this unfavourablem affect is an independent factor or simplys related to the effect of other factors remains to $\vec{\varphi}$ be determined. Nakao et $a l^{22}$ reported thate intense label uptake was seen in patients with pancreatic involvement. Conversely, Kamisawa et $a l^{21}$ found that immunolabelling was negative in all tumours located in the ampulla. Despite the larger number of tumourso in our series, we were unable to show any such association. We were unable to show any prognostic power for CEA, a finding which would not support the suggestion by Kamisawa et $a l^{21}$ that CEA has real, though weaker prognostic power than CA19.9. We have no: explanation for these conflicting findings Likewise, neither p53 nor Ki67 had any effect on prognosis in our series. We found that $\mathrm{p} 530$ protein had accumulated in $49 \%$ of our cases? This is similar to the rates reported in two othes series showing $\mathrm{p} 53$ positive results in five out of nine tumours of the ampulla of Vater $^{32}$ andE. in $66 \%$ of ampulla and common bile duct tumours. ${ }^{33}$ The unfavourable prognosis associ ated with such labelling in other tumours notably in tumours of the oesophagus, has nof been searched for previously in tumours of the ampulla of Vater. However, in a series of malignant tumours of the bile ducts andẹt ampulla, Teh $e a^{33}$ found that, unlike tumours of the gall bladder, there was no association between a low degree of differentiation an\& p53 positivity (a finding which may be relate to the lack of prognostic value for $\mathrm{p} 53$ found here). Finally, we were unable to show any prognostic value for $\mathrm{Ki} 67$ immunoreactivityo Other more recent studies have, however, beem. able to confirm this finding in colorectat cancer.

In conclusion, the findings in this series of 45 tumours of the ampulla of Vater treated by curative resection showed that 11 factors were significantly correlated with survival rate. Among these factors, jaundice and tumour localisation are well known for their prognostic 
power. For several others such as the histoprognostic classifications (Martin, ${ }^{6}$ Yamaguchi and Enjoji, ${ }^{7}$ Talbot et $a l^{8}{ }^{8}$ pTNM) there is a logical explanation for the relation with outcome. Other factors such as the type of mucin secreted, the presence of a non-invasive adenomatous component, and CA19.9 immunoreactivity are less well known. Some of these variables (mucin secretion, CA19.9 immunoreactivity on endoscopical biopsies $)^{21}$ or even depth of extension (using echoendoscopy or echolaparoscopy), ${ }^{34}{ }^{35}$ can be determined preoperatively and would therefore lead to the use of a neoadjuvant treatment. All these factors can also be evaluated postoperatively to determine whether adjuvant treatment is indicated. The aim of such adjuvant therapy would be to increase five year survival further by treating patients with factors of poor prognosis. For example, based on factors showing the highest level of significance in our series, the prognosis can be determined with further precision if two factors are associated. Thus for patients in stage 1 in the classification of Talbot $e t a l,{ }^{8}$ an assessment of sulphomucin secretion can identify non-secretors, who have a good prognosis (100\% survival at five years) and secretors with poor prognosis $(41 \%$ survival at five years). Likewise, CA19.9 immunoreactivity can distinguish between patients with good prognosis (CA19.9 negativity, five year survival $100 \%$ ) and those with poor prognosis (CA19.9 positivity, five year survival $36 \%$ ). However, this retrospective series with few patients can only provide tentative conclusions which must be validated in a prospective study. If validated, these findings could lead to clinical trials of adjuvant therapy proposed on the basis of histoprognosis.

1 Splinter TAW, Obertop H, Kok TC, Jeekel J. Adjuvant chemotherapy after resection of adenocarcinoma of the periampullary region and the head of the pancreas. A nonrandomized pilot study. $\mathcal{F}$ Cancer Res Clin Oncol 1989; 115: $200-2$.

2 Willet CG, Lewandrowski $\mathrm{K}$, Warshaw AL, Efird J, Compton CC. Resection margins in carcinoma of the head of the pancreas. Implication for radiation therapy. head of the pancreas. Imp

3 Willett CG, Warshaw AL, Convery K, Compton CC. Patterns of failure of pancreaticoduodenectomy for ampullary carcinoma. Surg Gynecol Obstet 1993; 176: 33-8.

4 Bakkevold KE, Arnesjo B. Adjuvant combination chemotherapy (AMF). Following radical resection of carcinoma of the pancreas and papilla of Vater - results of a controlled, prospective, randomised multicentre study. Eur ₹ Cancer 1993; 29: 698-703.

5 Blumgart JH, Kennedy A. Carcinoma of the ampulla of Vater and duodenum. Br 7 Surg 1973; 60: 33-40.

6 Martin ED. Anatomopathologie des tumeurs oddiennes. In: Marchal G, Hureau J, eds. Les tumeurs oddiennes. Paris: Masson, 1978: 35-52.

7 Yamaguchi K, Enjoji M. Carcinoma of the ampulla of vater. A clinicopathologic staging of 109 cases of carcinoma and 5 cases of adenoma. Cancer 1987; 59: 506-15.

8 Talbot IC, Neoptelemos JP, Shaw DE, Carr-Locke D. The histopatholoy and staging of carcinoma of the ampulla of Vater. Histopathology 1988; 12: 155-65.

9 Yamauchi H, Nitta A, Namiki T. Carcinoma of the papilla of Vater accompanied by non-invasive adenomatous com-
ponent (NAC). Tohoku $\mathcal{E} \operatorname{Exp} M e d$ 1990; 170: 147-56.

10 Bakkevold KE, Arnesjo B, Kambestad B. Carcinoma of the pancreas and papilla of Vater: presenting symptoms, signs, and diagnosis related to stage and tumour site. A prospective multicentre trial in 472 patients. Scand $f$ Gastroenterol 1992; 27: 317-25

11 Monson JRT, Donohue JH, McEntee GP, McIlrath DC, van $\mathrm{F}$ Heerden JA, Shorter RG, et al. Radical resection for carcinoma of the ampulla of Vater. Arch Surg 1991; 126: 353-7.

12 Allema JH, Reinders ME, Van Gulik TM, Van Leeuwen DJ, Verbeek PCM, de Wit LT, et al. Results of pancreaticoduodenectomy for ampullary carcinoma and analysis of prognostic factors for survival. Surgery 1995; 117: $247-53$.

13 Yamaguchi K, Enjoji M. Carcinoma of the ampulla of Vater. A clinicopathologic study and pathologic staging of 109 cases of carcinoma and 5 cases of adenoma. Cancer 1987; 59: 506-15.

14 Yamaguchi K, Enjoji M, Isunlyoshi $M$. Pancreatoduodenal carcinoma: a clinicopathologic study of 304 patients and immunohistochemical observation for CEA and CA19-9. f Surg Oncol 1991; 47: 148-54.

15 Sperti C, Pasquali C, Piccoli A, Sernagiotto, Pedrazzoli S. Radical resection for ampullary carcinoma: long-term results. Br f Surg 1994; 81: 668-71.

16 Yamaguchi K, Enjoji M, Kitamura K. Endoscopic biopsy has limited accuracy in diagnosis of ampullary tumors. Gastrointest Endosc 1990; 36: 588-92.

17 Ponchon T, Berger F, Chavaillon A, Bory R, Lambert R. Contribution of endoscopy to diagnosis and treatment of tumors of the ampulla of Vater. Cancer 1989; 64: 161-7.

18 Bakkevold KE, Kambestad B. Long term survival following radical and palliative treatment of patients with carcinoma of the pancreas and papilla of Vater. The prognostic factors influencing the long-term results. A prospective multicentre study. Eur F Surg Oncol 1993; 19: 147-61.

19 Delcore $\mathrm{R} J r$, Connor CS, Thomas JH, Friesen SR, Hermreck AS. Significance of tumor spread in adenocarcinoma of the ampulla of Vater. Am $\mathcal{f}$ Surg 1989; 158: 593-7.

20 Mori K, Ikei S, Yamane T, Yamaguchi Y, Katsumori T, Shibata Y, et al. Pathological factors influencing survival of carcinoma of the ampulla of Vater. Eur $\mathcal{F}$ Surg Oncol 1990; 16: 183-8.

21 Kamisawa T, Fukayama M, Koike M, Tabata I, Egawa N, Isawa $\mathrm{T}$, et al. Carcinoma of the ampulla of Vater: expression of cancer-associated antigens inversely correlated with prognosis. Am f Gastroenterol 1988; 83: 1118-23.

22 Nakao A, Harada A, Nonami T, Kishimoto W, Takeda S, Ito $\mathrm{K}$, et al. Prognosis of cancer of the duodenal papilla of Vater in relation to clinicopathological tumor of Vater in relation to clinicopathological

23 Dawson PJ, Connolly MM. Influence of site of origin and mucin production on survival in ampullary carcinoma. Ann Surg 1989; 210: 173-9.

24 Kozuka S, Tsubone M, Yamaguchi A, Hachisuka $K$. Adenomatous residue in cancerous papilla of Vater. Gut 1981; 22: 1031-4.

25 Hayes D, Bolton JS, Willis GW, Bowen JC. Carcinoma of the ampulla of Vater. Ann Surg 1988; 206: 572-7.

26 Kozuka S. Premalignancy of the mucosal polyps in the large intestine. I Histologic gradation of the polyp on the basis intestine. I Histologic gradation of the polyp on the basis of the epithelial pseudostratification and the
branching. Dis Colon Rectum 1975; 18: 483-93

27 Yamaguchi K, Enjoji M. Adenoma of the ampulla of Vater: putative precancerous lesion. Gut 1991; 32: 1558-61.

28 Yamauchi $H$, Nitta A, Namiki $T$, Inaamura $M$, Ichinohasama R. Different distribution of CA 19-9 in carcinomas arising in the papilla of Vater. An immunohistochemical study. Tokohu $\mathcal{f}$ Exp Med 1993; 170: 235-44.

29 Neoptolemos JP, Talbot IC, Shaw DC, Carr-Locke DL. Long term survival after resection of ampullary carcinoma is associated independently with tumor grade and a new is associated independently with tumor grade and a new staging classification that

30 Dawson PA, Patel J, Filipe MI. Variations in sialomucins in the mucosa of the large intestine in malignancy: a quantimet and statistical analysis. Histochem $\mathcal{f}$ 1978; 10: 559-72.

31 Kimura W, Ohtsubo K. Incidence, sites of origin, and immunohistochemical and histochemical characteristics of atypical epithelium and minute carcinoma of the papilla of Vater. Cancer 1988; 61: 1394-402.

32 Scarpa A, Capelli P, Zamboni G, Oda T, Mukai K, Bonetti F, et al. Neoplasia of the ampulla of vater. Am F Pathol 1993; 142: 1163-72.

33 Teh M, Wee A, Raju C. An immunohistochemical study of p53 protein of gallbladder and extrahepatic bile duct/ ampullary carcinomas. Cancer 1994; 74: 1542-5.

34 Giovannini M, Seitz JF. Endoscopic ultrasonography with a linear-type. Echoendoscope in the evaluation of 94 patients with pancreatobiliary disease. Endoscopy 1994; 26: 579-85.

35 John TG, Greig JD, Carter DC, Garden OJ. Carcinoma of the pancreatic head and periampullary region. Tumor staging with laparoscopy and laparoscopic ultrasonography. Ann Surg 1995; 221: 156-64. 